\title{
Fourier-based contour descriptors to relax positional standardization of the otolith images in AFORO queries
}

\author{
Pere Marti-Puig ${ }^{1}$, Amalia Manjabacas ${ }^{2}$, Antoni Lombarte ${ }^{2}$ \\ ${ }^{1}$ Grup de Processament del Senyal. University of Vic (UVIC-UCC), Vic, Catalonia, Spain. \\ (PM-P) (Corresponding author) E-mail: pere.marti@uvic.cat. ORCID iD: https://orcid.org/0000-0001-6582-4551 \\ ${ }^{2}$ Institut de Ciències del Mar, CSIC, Barcelona, Catalonia, Spain. \\ (AM) E-mail: manjabacas@icm.csic.es. ORCID iD: https://orcid.org/0000-0001-8685-8697 \\ (AL) E-mail: toni@icm.csic.es. ORCID iD: https://orcid.org/0000-0001-5215-4587
}

\begin{abstract}
Summary: The otolith digital catalogue AFORO allows unknown otoliths to be classified automatically by using a comparison with its classified records. To do this, the otolith's contour, which is extracted from an image, is used. In AFORO, otolith images follow a strict positional normalization. Only the left sagitta is considered, and the images must show the internal side of the whole otolith, with the sulcus acusticus visible, the dorsal side (D) placed in the dorsal position and the rostral side $(\mathrm{R})$ placed on the right. The otolith in the incoming image to be classified must also follow the same positional normalization. Variations from the reference position worsen the classification results. In this article, robust contour descriptors are proposed to extend this functionality of AFORO to the images of otoliths that are poorly normalized, contain rotations, are entirely inverted or came from the right rather than the left sagitta. These descriptors are based on the discrete Fourier transform and could extend the classification functionality to incoming images that are taken and sent, for instance, from smartphones in a wide range of working conditions.
\end{abstract}

Keywords: otoliths; 2D shape descriptors; contour descriptors; rotation invariance; fast Fourier transforms.

Descriptores de contorno basados en Fourier para relajar la estandarización posicional de las imágenes de otolitos en las consultas AFORO

Resumen: El catálogo digital de otolitos AFORO permite la clasificación automática de otolitos desconocidos mediante la comparación con sus registros clasificados. Para ello, se utiliza el contorno del otolito, que se extrae de una imagen. En AFORO, las imágenes de otolitos siguen una estricta normalización posicional. Sólo se considera la sagita izquierda, y las imágenes deben mostrar la cara interna de todo el otolito, siendo visible el surco acústico (SA), con la cara dorsal (D) colocada hacia arriba y el rostrum $(\mathrm{R})$ a la derecha. De la misma manera, el otolito en la imagen entrante a clasificar debe seguir la misma normalización posicional. Las variaciones respecto a la posición de referencia empeoran los resultados de la clasificación. En este trabajo se proponen descriptores de contorno robustos para extender esta funcionalidad de AFORO a las imágenes de otolitos mal normalizados, que contienen rotaciones, totalmente invertidos o que proceden de la sagita derecho (no del izquierdo). Estos descriptores se basan en la DFT (transformada discreta de Fourier) y podrían ampliar la funcionalidad de clasificación a imágenes entrantes tomadas y enviadas, por ejemplo, desde teléfonos inteligentes y en condiciones de trabajo muy diferentes.

Palabras clave: otolitos; descriptores de forma 2D; descriptores de contorno; invariancia de rotación; transformada rápidas de Fourier.

Citation/Como citar este artículo: Marti-Puig P., Manjabacas A., Lombarte A. 2020. Fourier-based contour descriptors to relax positional standardization of the otolith images in AFORO queries. Sci. Mar. 84(1): 000-000. https://doi.org/10.3989/ scimar.04961.15A

Editor: V.M. Tuset.

Received: June 6, 2019. Accepted: November 12, 2019. Published: February 6, 2020.

Copyright: (c) 2020 CSIC. This is an open-access article distributed under the terms of the Creative Commons Attribution 4.0 International (CC BY 4.0) License.

\section{INTRODUCTION}

Otoliths are calcareous structures found in the inner ear of osteichthyan fishes, and the shape and structure are species-specific (Koken 1884, Chaine and Duvergier 1931, Schmitd 1969). Evidence of this has long existed (Hecht 1982, Baldás et al. 1997, Volpedo and Echeverría 2000) and is expanding as new collections 
are analysed (Baremore and Bethea 2005) and new studies appear (Campana 2004, Furlani et al. 2007, Tuset et al. 2008). Otoliths have been used mainly in the identification of stocks (Bird et al. 1986) and species (Schmidt 1969); phylogenetic (Gaemers 1984) and palaeontological (Nolf 1985) food webs (Fitch and Brownell 1968); eco-morphological (Lombarte and Fortuño 1992) palaeoecology (Cartes et al. 2017); and even sex identification and ageing (Cardinale et al. 2004). In trophic ecology, otoliths are used to identify species in ichthyophageal stomachs and faeces (Pierce and Boyle 1991, Bustos et al. 2012, 2014). This specific association between the morphology and the species to which they belong allows for the exact determination of the components of the diets of predatory fish animals. There are three pairs of otoliths in the ear, but the sagitta is the otolith with the most significant morphological variability and is therefore the one most studied. The sagitta is also generally used for this type of study because in non-otophysian fishes it is larger than the rest of the otoliths (Pierce et al. 1991), which allows for better observation of its morphology, and it does not suffer the process of calcium reabsorption (Casselman 1981).

The AFORO website (http://aforo.cmima.csic. es) is mainly an open online catalogue of images of sagitta otoliths. Throughout the text, we refer to any sagitta otolith as "otoliths" for simplicity. This website has been in development since 2003 (Lombarte et al. 2006), two decades after the first otoliths were studied using a Fourier analysis of contours (Messieh et al. 1989, Bird et al. 1986, Doering and Ludwing 1990), and offers high-resolution fish otolith images with complete morphometric information, including a shape analysis module that provides mathematical contour descriptors, such as the Fourier transform (FT), curvature scale space (CSS) and wavelet transform (WT) (Parisi-Baradad et al. 2005, 2010, Piera et al. 2005).

At present, the AFORO database contains 5793 high-resolution images that correspond to 1776 species, and its software tools have been used for otolith atlases (Tuset et al. 2008, Sadighzadeh et al. 2012), morphological indices (Tuset et al. 2006), stock identification (Capoccioni et al. 2011, Tuset et al. 2013, Sadighzadeh et al. 2014), automatic species identification (Parisi-Baradad et al. 2005, 2010), eco-morphological studies (Cruz and Lombarte 2004, Lombarte and Cruz 2007, Sadighzadeh et al. 2014), archaeological information (Rodney 2009), biodiversity (Tuset et al. 2016), and, particularly, prey identification (Veiga et al. 2011, Neves et al. 2012, Otalora-Ardila et al. 2014). Furthermore, it contains a small 3D repository of otoliths (Marti-Puig et al. 2015) of the family Sciaenidae (Perciformes), which are specialized in acoustic communication (Cruz and Lombarte 2004) and have an exceptional sulcus acusticus (SA) (Smale 1995, Volpedo and Echevarria 2000, Monteiro et al. 2005), as reported widely (Ramcharitar et al. 2006, Tuset et al. 2008, Lin and Chang 2012).

Currently, AFORO's functionality of automatic identification of fish species and populations is based on $2 \mathrm{D}$ otolith closed contours. It works by comparing the contour that is extracted from an external query image against those that are in the AFORO database. All images in the database have been registered following a strict acquisition protocol, which is also required for incoming query images. However, small errors in registration of the query image are common. These introduce small rotations of the contour resulting in misalignments in the contour reference, which in turn decrease the accuracy of the classifier. Furthermore, two more critical factors cause the system to fail: otoliths in the incoming image appear rotated by approximately 180 degrees with respect to normalization because the rostrum (a part of the otolith) has been misidentified or because the incoming images have been acquired under other normalization criteria.

In addition, in some practical applications only the right sagitta is available, whereas the AFORO database only stores data on the left sagittae. To improve the automatic otolith recognition functionality that is provided by AFORO, in this paper, we study how to relax and also to completely avoid the normalization that is required for images and we explore a strategy for classifying the right sagitta by taking advantage of contour symmetries it has with the left sagitta. This is done by proposing descriptors that take advantage of the well-known discrete Fourier transform (DFT) coefficients and their properties (Proakis and Manolakis 1996). The DFT is very efficient when working with periodical functions, and the contours of the figures can be interpreted as periodical functions by continually moving through it. Features that are based on the CSS or WT are susceptible to rotations and variations in the contour sampling point, and their efficiency decreases when the standardization of input information is slightly mismatched (Marti-Puig and Reig-Bolano 2016). The potential and significant advantage of Fourier methods is that they can relate rotations in space to identify them in other changes in the transformed domain. In the same way, in a periodic time-series, DFT properties also identify positional displacements in the transformed domain. In this paper, we explore those properties to achieve robustness against positional standardization misalignments and the cost of avoiding standardization completely. Some preliminary ideas, such as the use of the major ellipse axis, can be found in Marti-Puig and Reig-Bolano (2016). In this seminal work, a seven-step algorithm was established to perform the query and to analyse the effect of rotation (concerning positional standardization) on the classification rate in the case of a DFT-based parameterization. However, as experiments take the contours from the AFORO database, all the series that defined the contours started at the same reference point. When the outline is extracted from an unknown image in which the otolith may appear rotated, it is necessary to adjust the starting point of the series because the first point of the contour that is found when scanning the image matches the reference point. The contribution of the proposed parameterization in the present work is twofold, in the sense that the same parameters include the rotational normalization and the change in the sampling origin. The use of complex coefficients allows the properties of the DFT to be fully 
exploited and a compact set of features for automatic identification to be established.

To highlight the contributions of this work and point out the differences from that of Marti-Puig and ReigBolano (2016), note that the earlier work used elliptic Fourier descriptors (EFDs), initially proposed by (Kuhl and Giardina 1982). Using EFDs, each mode, each "frequency" of contour variation, requires four real coefficients. The original EFD formulation is dependent on contour position, scale, orientation, the starting point of sampling, the sampling direction (clockwise/ anti-clockwise) and the number of samples per contour. In Marti-Puig and Reig-Bolano (2016), the way to relate the EFD coefficients $\left(a_{k}, b_{k}, c_{k}, d_{k}\right)$ of a contour with the same contour rotated, displaced or scaled $\left(\mathrm{a}_{\mathrm{k}}{ }^{,}, \mathrm{b}_{\mathrm{k}}{ }^{\prime}, \mathrm{c}_{\mathrm{k}}{ }^{\prime}\right.$, $\mathrm{d}_{\mathrm{k}}{ }^{\prime}$ ) follows the matrix notation proposed in Nixon and Aguado (2008, p. 307). Note that Nixon and Aguado (2008, p. 304) also proposed invariant contour descriptors derived from EFDs, which reduce four real EFDs $\left(a_{k}, b_{k}, c_{k}, d_{k}\right)$ into one $\left(f_{k}\right)$. Those $f_{k}$ are invariant to rotations, sampling point and direction and symmetries. However, their use for classification of otoliths provides very poor results compared with EFDs with handmade positional standardization (Marti-Puig and Reig-Bolano 2016). Other invariant descriptors are those proposed in (Zhang and Lu 2001), which eliminate the phase of DFT coefficients and preserve the modulus. Unfortunately, they work similarly to those pointed out in our formula (9) or those in Nixon and Aguado (2008). To avoid losing the ability to classify otoliths obtained by EFDs and positional standardization, which is manual, Marti-Puig and Reig-Bolano (2016) proposed an automatic positional contour normalization. The method was based on finding the major fundamental ellipse axis in which the contour can be decomposed, and the angle of this axis with the horizontal. This angle is used to rotate the contour in order to keep the principal ellipse axis horizontal. This strategy is independent of the human criteria and keeps the classification rate close to the results obtained by an expert doing the standardization procedure very carefully. That procedure works for rotations that do not exceed angles of $\pm 90^{\circ}$ from manual positional standardization.

In the present work, we employ the DFT coefficients, which unlike EFDs are complex, and we perform all the operations presented in Marti-Puig and Reig-Bolano
(2016) much more efficiently because the DFT can be computed via the fast Fourier transform algorithm. We highlight some results related to the DFT formulation:

- A closed formula for the angle $\theta$ involved in the automatic positional normalization.

- A closed formula to find a starting point of sampling $\hat{\mathrm{k}}$.

- The procedure to apply both sampling and positional standardizations by performing operations directly on the phase of the DFT coefficients.

- A way to deal with rotations higher than $\pm 90^{\circ}$ and also with symmetries.

The most relevant result is that the new strategy maintains the classification rate of otoliths of nonstandardized inputs very close to that obtained when the contours are manually orientated by an expert and the samples are prepared for this purpose. The experiments were performed with the same database and the same classifier as in Marti-Puig and Reig-Bolano (2016) to facilitate comparisons.

The work is organized as follows: the Materials and Methods section covers the AFORO image acquisition protocol required to correctly position the otolith, the derivation of the proposed descriptors robust to rotations of $\theta\left(|\theta|<90^{\circ}\right)$, the number of points that were used to represent contours, some shape symmetries and their relation to the proposed descriptors, a baseline to achieve invariance and, finally, the method of classification and validation that was employed. The Results section presents the results under two frameworks: one in which the AFORO user applies positional normalization and in which the errors that are introduced with respect to the desired reference are small; and one that evaluates the recognition performance that could be achieved without positional standardization. We conclude the paper with some discussion.

\section{MATERIALS AND METHODS}

\section{Test dataset}

The test material comes from the AFORO database, which is regularly updated and at present $(07 / 06 / 2018)$ contains a total of 5793 high-resolution images corresponding to 1776 species and 238 families from oceans all around the world. The specimens selected for the
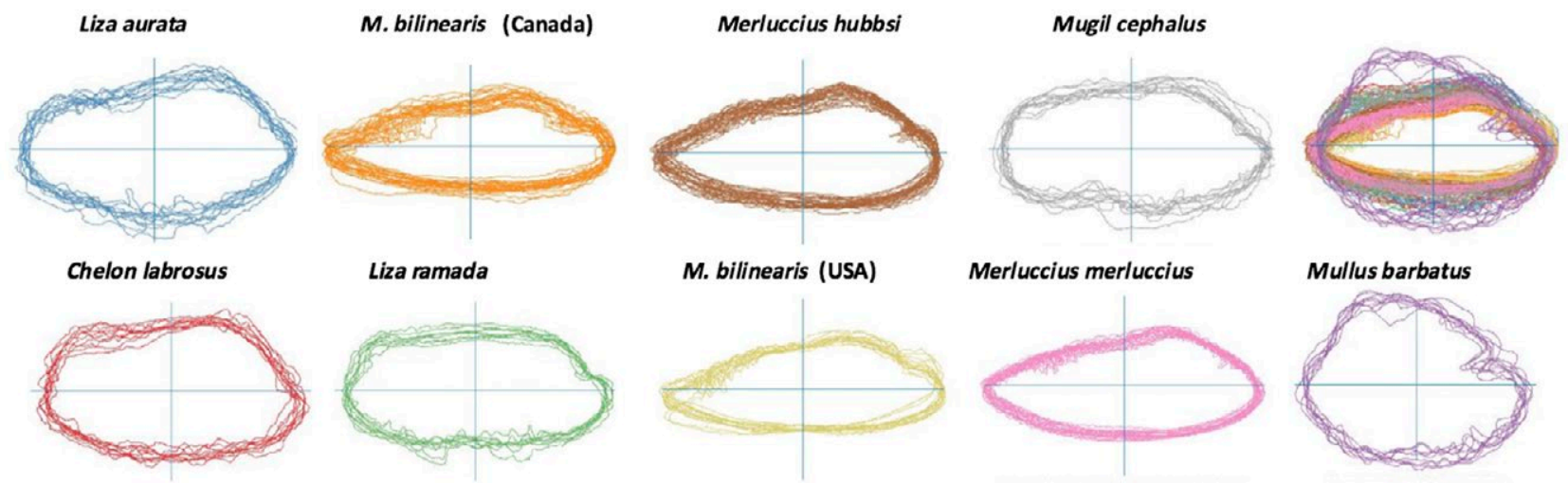

Fig. 1. - Overlapping contours by classes. On the upper-right side, the superposition of all shapes. 


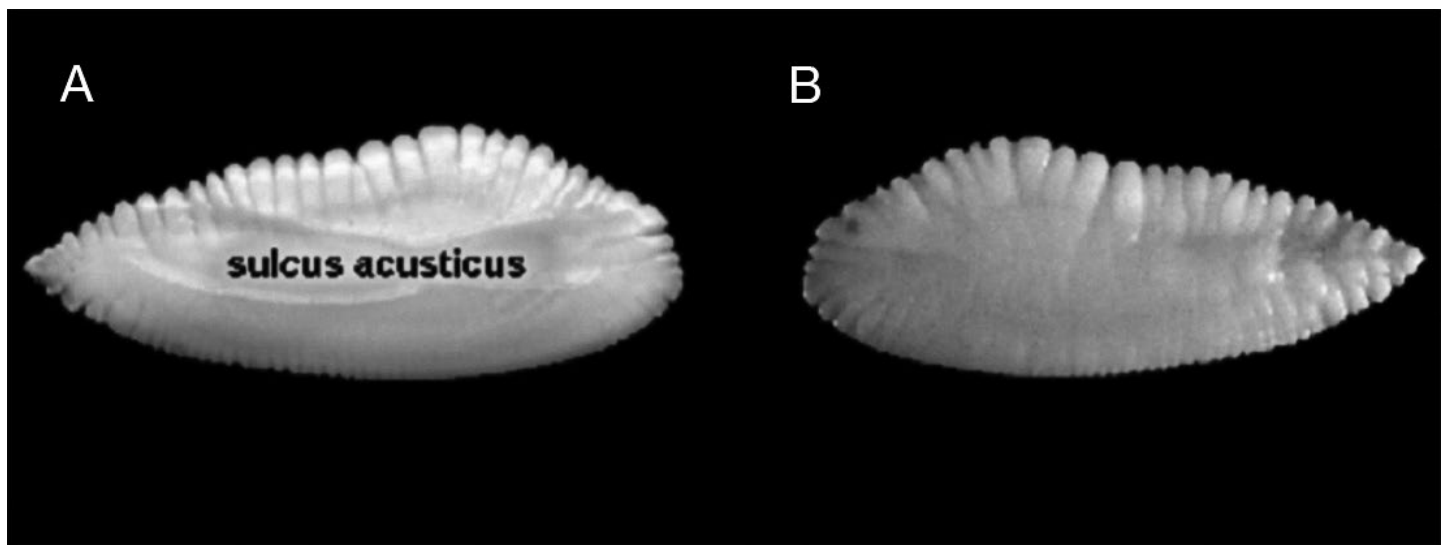

Fig. 2. - Concerning the positional normalization, the image must be from the internal side of the whole otolith. In A, the right side; the medial or internal side showing the sulcus acusticus. In B, the wrong (external) side.

database are focused on representing all the possible variability within each species, such as age, length, sex and stock. The approach presented in this paper was tested with 134 otoliths from eight different species but was optionally divided into eight or nine classes. To compare the results with that of a previous study (Reig-Bolaño et al. 2010), we took the same set of species (number of specimens in brackets): Chelon labrosus (10), Liza aurata (11), Liza ramada (9) and Mugil cephalus (10) from the family Mugilidae: Merluccius hubbsi (28), Merluccius merluccius (19) and Merluccius bilinearis with specimens collected in Canada (24) and in USA (14) from the family Merlucciidae and Mullus barbatus (9) from the family Mullidae. See Figure 1.

\section{Image acquisition, AFORO positioning protocol}

1. Upload only one image of the left sagitta, as shown in Figure 2. The image must be from the internal side (medial or proximal) of the whole otolith. The internal side shows the SA (a groove along the surface of the sagitta).

2. To obtain a good representation of the sagitta contour, the image must be well contrasted. If possible, the background should be homogeneously black.
3. Sagitta position. The dorsal side (D) of the otolith must be placed facing upwards in the image. The anterior or rostral side (R) must be located on the right side of the image. Figure $3 \mathrm{~A}$ shows the right position.

\section{Proposed contour descriptors for rotations between $-90^{\circ}$ and $90^{\circ}$ concerning positional normalization}

Consider a contour sampled in counter-clockwise direction in which $x_{k}$ and $y_{k}$ are the $x$ and $y$ coordinates and $\mathrm{j}=\sqrt{-}-1$. In a complex form, it can be expressed as:

$$
s_{k}=x_{k}+j y_{k} k=0,1, \ldots, N-1
$$

By applying DFT, we have the transformed coefficients $f_{1}$ as follows:

$$
f_{l}=\sum_{k=0}^{N-1} x_{k} e^{-j \frac{2 \pi}{N} k l} l=0,1, \cdots, N-1
$$

Thus, the original $s_{k}$ can be written by $f_{l}$ using the inverse discrete Fourier transform (IDFT) as follows:

$$
S_{k}=\frac{1}{N} \sum_{l=0}^{N-1} f_{l} e^{j \frac{2 \pi}{N} k l} l=0,1, \cdots, N-1
$$

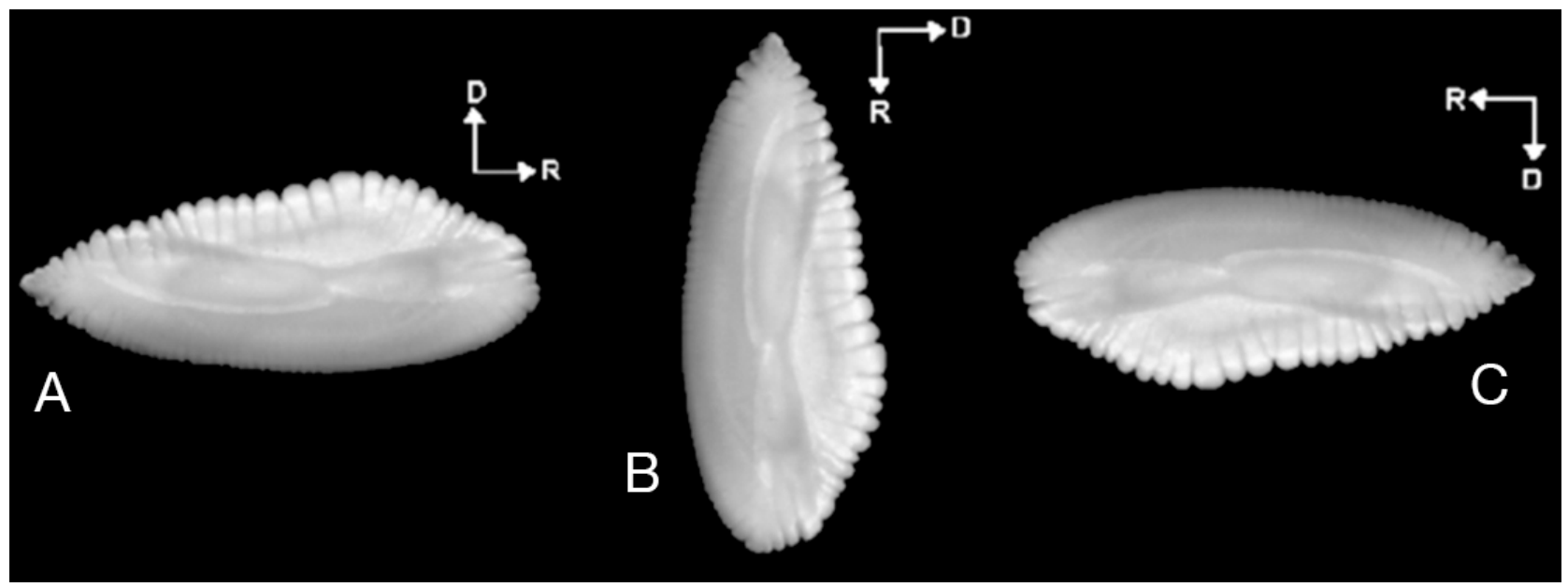

Fig. 3. - Concerning the positional normalization of left sagitta, the otolith dorsal side (D) must be placed in the dorsal position of the image and the anterior or rostral side $(\mathrm{R})$ on the right side. A, right position; $\mathrm{B}$, wrong position 1 ; $\mathrm{C}$, wrong position 2 . 
Note from (2) that $f_{0}=N\left(x_{c m}+j y_{c m}\right)=N \cdot s_{c m}$, where $\left(x_{c m}, y_{c m}\right)$ is the centre of the masses of the contour. When $s_{c m}=0$, the contour is centred at $(0,0)$. To obtain an invariance of the translation, in the context of Fourier descriptors, we must merely impose $f_{0}$ to be 0 . Any reconstruction of $f_{k}$, with $f_{0}=0$, will reconstruct the contour of the original shape centred on the coordinate origin.

Note that at this point we do not assume any particular position to start contour sampling. In fact, contour sampling could start at any point. We merely begin from any point belonging to the contour, with the sampling completed counter-clockwise.

With the aim of evolving the descriptors, let us first look at how we can describe the first ellipse upon which the contour is centred. It would be the most straightforward reconstruction of the original outline performed by only two complex coefficients, $f_{1}$ and $f_{N-1}$. From (3), the ellipse $e_{k}$ takes the following form:

$$
\begin{gathered}
e_{k}=\frac{1}{N}\left(f_{1} e^{j \frac{2 \pi}{N} k}+f_{N-1} e^{j \frac{2 \pi}{N}(N-1) k}\right)= \\
=\frac{1}{N}\left(f_{1} e^{j \frac{2 \pi}{N} k}+f_{N-1} e^{-j \frac{2 \pi}{N} k}\right) k=0,1, \cdots, N-1
\end{gathered}
$$

Let us write $f_{1}$ and $f_{N-1}$ in polar form: $f_{1}=\left|f_{1}\right| e^{j \phi_{1}}$ and $f_{N-1}=\left|f_{N-1}\right| e^{j \phi_{N-1}}$. The two terms of $e_{k}$ in (4) are two vectors that move in the complex plane, in the increment of $k$, at the same speed but in the opposite directions. When these vectors intersect with the same phase, the resulting vector contribution marks the point of the major ellipse axis; alternatively, when they are in phase opposition, their vector sum marks extreme conforming of the minor axis. These crossings occur twice, each time when the vectors complete $360^{\circ}(\mathrm{N}$ samples) by marking both sides of the major and minor axes of the ellipse. Thus, from (4), it is easy to see that the modulus of the major ellipse axis measures $2 / N\left(\left|f_{1}\right|+\left|f_{N-1}\right|\right)$ and it is reached at point $\hat{k}$

$$
\hat{k}=\frac{N}{4 \pi}\left(\phi_{N-1}-\phi_{1}\right)
$$

which is obtained by equalizing the phases of both terms in Expression (4). Thus, by considering $f_{1}$ and $f_{N-1}$ in polar form, we have

$$
\frac{2 \pi}{N} \hat{k}+\phi_{1}=\frac{-2 \pi}{N} \hat{k}+\phi_{N-1}
$$

and by isolating $\hat{k}$, (5) becomes direct. A positive value of $\hat{k}$ represents a clockwise displacement of $\hat{k}$ samples from the position of the first sample of the contour sequence, while a negative value means a clockwise displacement. Therefore, the final value must be taken modulo $N$ in the $0, \cdots, N-1$ range. In the ellipse, the two values that limit the extremes of the principal axis are separated N/2 samples. Finally, we choose the value that meets $\operatorname{Real}\left(e_{\hat{k}}\right)>0$, which is the one that is located in the region that is formed by the first and fourth quadrants. Thus, angle $\theta$, which is used in the first/fourth quadrant region of the major ellipse axis with respect to the horizontal, is as follows:

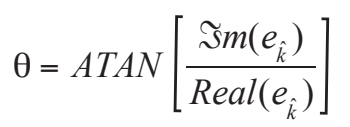

In the range of $-\pi / 2<\theta<\pi / 2$, we can correct the angle of rotation in the frequency domain by multiplying each coefficient by $e^{-j \theta}$.

As in badly normalized incoming images we do not control the starting contour sampling point, we change it in order, beginning with the point $\hat{k}$, which will pass to the first sample of the sequence. This can be done by DFT in the coefficient domain by multiplying each $l$ component by

$$
e^{-j \frac{2 \pi}{N} \hat{k}}
$$

according to the DFT property:

$$
F\left[s_{k-\hat{k}}\right]=f_{l} e^{-j \frac{2 \pi}{N} \hat{k} l} .
$$

We achieve scale invariance by normalizing the coefficients by half of the major principal ellipse axis. Therefore, the new proposed coefficients take the following form:

$$
C_{l}=\frac{f_{l}}{\left|f_{1}\right|+\left|f_{N-1}\right|} e^{-j \frac{2 \pi}{N} \hat{k}-j \theta}, l=1, \cdots, N-1
$$

Note that if we apply an IDFT directly to the $C_{l}$ coefficients previously described in Equation (7), with $C_{0}=0$, we recover the shape of the otolith. Thus, if in the original figure the otolith was rotated between $-90^{\circ}$ and $90^{\circ}$ concerning the required positional normalization, the recovered contour appears to be represented in the way that the principal ellipse axis remains horizontal with the rostrum (R) in the right position, as is represented in Figure 4A, which matches the positional normalization that is required in AFORO. However, if in the incoming image the otolith appears to be rotated between $90^{\circ}$ and $270^{\circ}$ concerning the required normalization, then the reconstructed contour appears to be rotated $180^{\circ}$, with the rostrum to the left and the dorsal part at the bottom of the image, as shown in Figure 4B.

Note that from the result of directly applying the contour descriptors defined in (7), the initial sampling point does not necessarily fall at the zero phase position (on the real axis), but varies slightly. A variant of
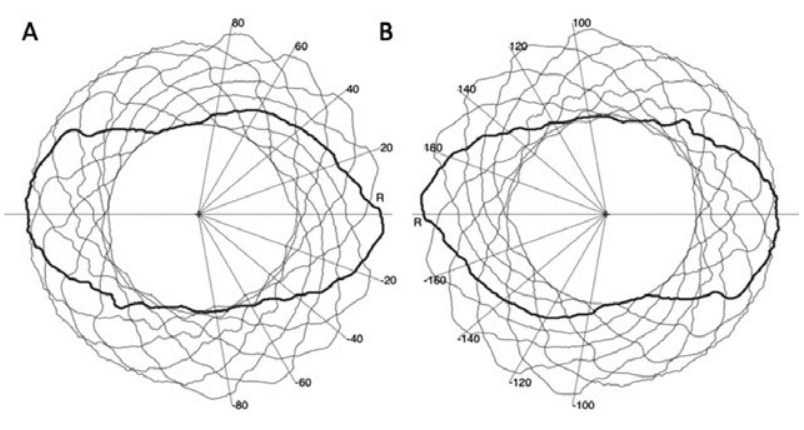

Fig. 4. - In bold letters, representation of the reconstructed contours from $C_{l}$ coefficients when, in the incoming image, the otolith was rotated with respect to the AFORO positional normalization by $\mathrm{A}$, between $-90^{\circ}$ and $90^{\circ}$ and $\mathrm{B}$, between $90^{\circ}$ and $270^{\circ}$. 
A

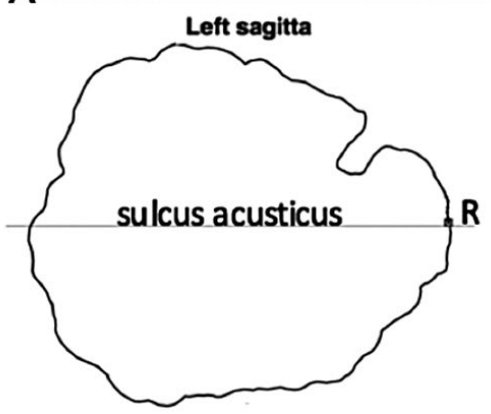

C

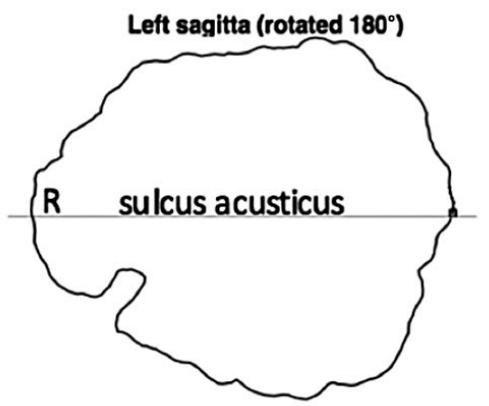

B

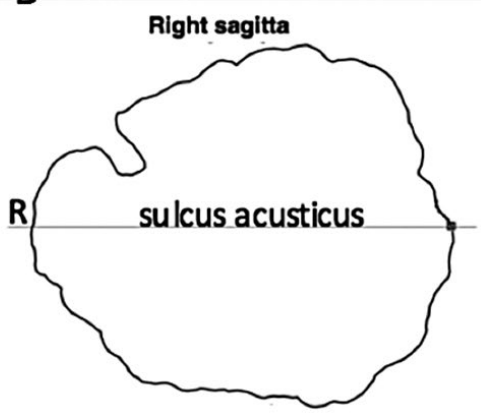

D

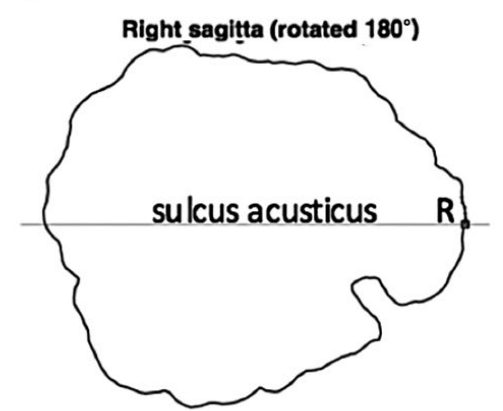

Fig. 5. - The contour of A, the left sagitta obtained following the AFORO positional normalization; B, the left sagitta rotated $180^{\circ}$ with respect to the AFORO positional normalization; and $\mathrm{C}$, the right sagitta showing the sulcus acusticus visible. This silhouette is a mirror reflection of that in A, concerning point $\mathrm{R}$, and it is related to the left sagitta silhouette obtained by hiding the face of the sulcus acusticus and keeping the rostrum on the left side of the image. $\mathrm{D}$, the right sagitta rotated by $180^{\circ}$ with respect to the shape in $\mathrm{C}$ is related to the shape of the left sagitta contour in $\mathrm{B}$, which was obtained by hiding the face of the sulcus acoustics.

the descriptors is proposed in (8), where the angle is corrected, but sampling is forced at the point closest to the horizontal axis (the zero phase point).

$$
C_{l}=\frac{f_{l}}{\left|f_{1}\right|+\left|f_{N-1}\right|} e^{-j \theta}, \quad l=1, \cdots, N-1
$$

This second option allows the symmetries represented in Figure 7 to be related within the spatial and transformed domains according to the expressions that are defined in the next section. Note that the positional normalization used is highly adapted to the $\theta$ correction given in (6), as most angles fall within a \pm 5 degree range.

\section{Contour length resampling}

To be able to compare the spectral content between contours, they are resampled so that they all have the same number of $N$ points. In the experiments that were conducted, the values of $\mathrm{N}=256,512$ and 1024 were selected.

\section{Shape symmetries and their relationship with the proposed descriptors}

In this section, we show the relationship between reconstructions from the proposed coefficients that were obtained for otolith contours depending on their orientation in the image. Figure 5 shows four cases that all show the face on which the SA appears. Cases a) and b) correspond to the reconstructions of the left sagitta when it is rotated from positional normalization at an angle of between $-90^{\circ}$ and $90^{\circ}$ and between $90^{\circ}$ and $270^{\circ}$, respectively. Cases c) and d) correspond to the reconstructions of the right sagitta (not used in AFORO) when it is rotated between $-90^{\circ}$ and $90^{\circ}$ and between $90^{\circ}$ and $270^{\circ}$, respectively. Note that the contour in c) is the one that was obtained by turning the otolith in a) to hide the SA. The same is true for b) and d). The desirable silhouette for the AFORO system is a). It is important to note that all sequences that describe the contours start at a point on the real axis (with phase 0 ). We insist on this detail because we can begin the same contour at any other position, but, as is well known, changing the sampling starting point changes the phase of the DFT coefficients. The rest of the contours can appear in the system if, for example, a very significant error is made in the positional normalization; if the otolith is photographed with SA not visible, or if a mistake enters the right otolith. Although the silhouettes are different, there are symmetries between them. The descriptors that reconstruct them also show essential relationships. If we take as a reference the descriptors of contour $a$ ) as $C_{l}$, the rest of the descriptors for contours $b$ ), $c$ ), and $d$ ) can be written regarding $C_{l}$ according to the following relations that involve the (IDFT) function:

$$
\begin{gathered}
\operatorname{idft}\left(C_{l}\right) \rightarrow \text { contour } a \\
\operatorname{idft}\left((-1)^{l+1} \cdot C_{l}\right) \rightarrow \text { contour } b \\
\operatorname{idft}\left((-1)^{l+1} \cdot C^{*}\right) \rightarrow \text { contour } c \\
\operatorname{idft}\left(C^{*}{ }_{l}\right) \rightarrow \text { contour } d
\end{gathered}
$$


The super index ( $)^{*}$ stands for the complex conjugate operation. When calculating the descriptors of a randomly rotated contour $\left(360^{\circ}\right)$ that has (or does not have) a possible specular symmetry, it will always fit with one of the four previous expressions. In the literature we find other ways of dealing with symmetries, such as those described in Agarwala et al. (2011), but our proposal is very simple and robust.

\section{Invariant Fourier descriptors for rotations, symmetries and the initial sampling point}

We can see that the modules of the coefficients coming from the four expressions (corresponding to contours $a$ to $d$ ) presented in the previous section are the same. Therefore, a group of descriptors that are independent of the rotations, symmetries and the initial sampling point can be:

$$
M_{l}=\left|C_{l}\right|=\frac{\left|f_{l}\right|}{\left|f_{1}\right|+\left|f_{N-1}\right|}, \quad l=1, \cdots, N-1
$$

Expression (9) is similar to the one proposed in Zhang and $\mathrm{Lu}$ (2001) to obtain invariance and has a similar performance in classification tasks as those proposed by Nixon and Aguado (2008), as it was reported in (Marti-Puig and Reig-Bolano 2016).

\section{A compact and efficient set of features}

Features must represent the contour efficiently, and through them, the amount of information to describe it must be much less than the complete information that defines the silhouette. The most energy-intensive DFTbased coefficients are those at the beginning and end of the sequence. An efficient representation requires the number $2 L_{c}$ to be much lower than $N$. For automatic recognition purposes, after a specific $L_{c}$ value, the recognition rate is no longer improved. The selected $k$ indices range from 1 to $L_{c}$ and from $L_{c}-N$ to $N-1$. Note that the values of $C_{l}$ are complex.

\section{The K-nearest neighbour classifier (K-NN) and leave-one-out cross-validation (LOOCV)}

The $k$-nearest neighbour algorithm, which is one of the most straightforward classifiers, is used in our classification stage. According to the $k$-NN strategy, a new specimen that is characterized as a vector of characteristics is classified according to the governing class of their $k$ well-classified nearest neighbours. In the present case, the proximity between elements is calculated by the Euclidean metric.

The LOOCV strategy is the option used to evaluate the performance of the classifier. LOOCV uses a single observation from the original set as the validation data and the remaining observations as training data. All the elements are tested against the rest, so we know how each particular element is classified. With LOOCV, all the observations are used for both training and validation, with each observation being used once for validation. In datasets in which there are few elements per class, as usually happens in our case, LOOCV seems to be an appropriated strategy.

\section{RESULTS}

Several experiments were conducted to evaluate the performance of the presented descriptors according to two different scenarios. The first scenario considers that the incoming image (the query image) has been taken by someone with sufficient knowledge to correctly distinguish the left sagitta, to determine the face of the otolith that shows the SA and to orient it correctly according to the indications of AFORO. In this scenario, the errors are only minor orientation errors and will always be between $-90^{\circ}$ and $+90^{\circ}$. In the second scenario, we want to evaluate the capacity for identifying species just from the silhouette of the otolith, regardless of whether it is the right or the left sagitta and regardless of its orientation in the image. Therefore, no normalization positions are considered at all.

Common to all experiments, the effectiveness of the proposed contour descriptors will be evaluated using a K-NN classification test with $(\mathrm{K}=1)$ and using LOOCV. The first scenario was also used to assess the impact on the classifier accuracy depending on the number of coefficients and the number of points that are employed to represent the contour. To do this, we codified all the contours under a test, the coefficients $C_{l}$ were calculated according to the expression (8) and the initial contour sampling point was forced, as has been described. The coefficient $C_{0}$ was eliminated, and the $2 L$ coefficients with indices 1 to $L$ and $N-L$ to $N-1$ were selected. These coefficients are complex, so the descriptors that are used are the real parts followed by the imaginary parts of those $C_{l}$.

LOOCV involves selecting one contour and deleting its coefficients from the group. We apply a random rotation of between $-90^{\circ}$ and $90^{\circ}$ to that contour. We codify it by applying (8) and selecting the same $2 L$ coefficients as those considered, ordering real and imaginary parts as explained above, and classifying it using $k$-NN with Euclidian distance and $k=1$. This operation is repeated for all contours in several ways, and the average results are obtained as shown in Figure 6. Note that in Figure 6B we have considered the Merluccius bilinearis collected in Canada and the Merluccius bilinearis collected in the USA as belonging to two different classes, while in Figure 6A, they belong to the same class. In both cases, the abscissas represent the number \# of real coefficients that were used (so a complex coefficient splits into two real coefficients). The accuracy is represented by the ordinates. In both subplots, the accuracy in the function of the number of components that are employed is computed for the same contours as those sampled at $\mathrm{N}$ equal to 256 , 512 and 1024 points. The results suggest that contours represented by 1024 points achieve better accuracy in all cases. In addition, given a certain number of coefficients, the accuracy no longer improves, being an optimum of 28-32 real coefficients for the case of contours that are represented with 1024 points. 
A

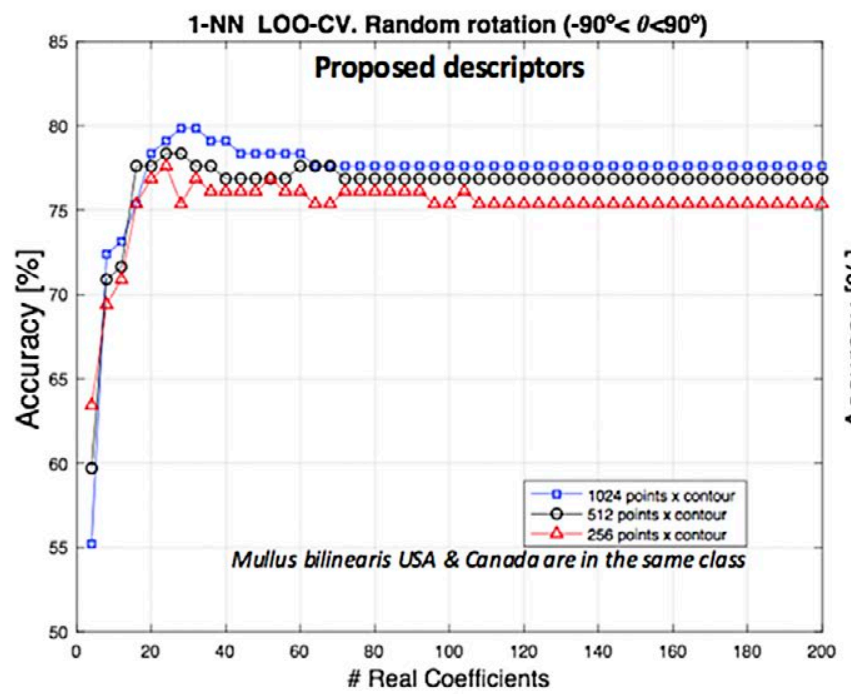

B

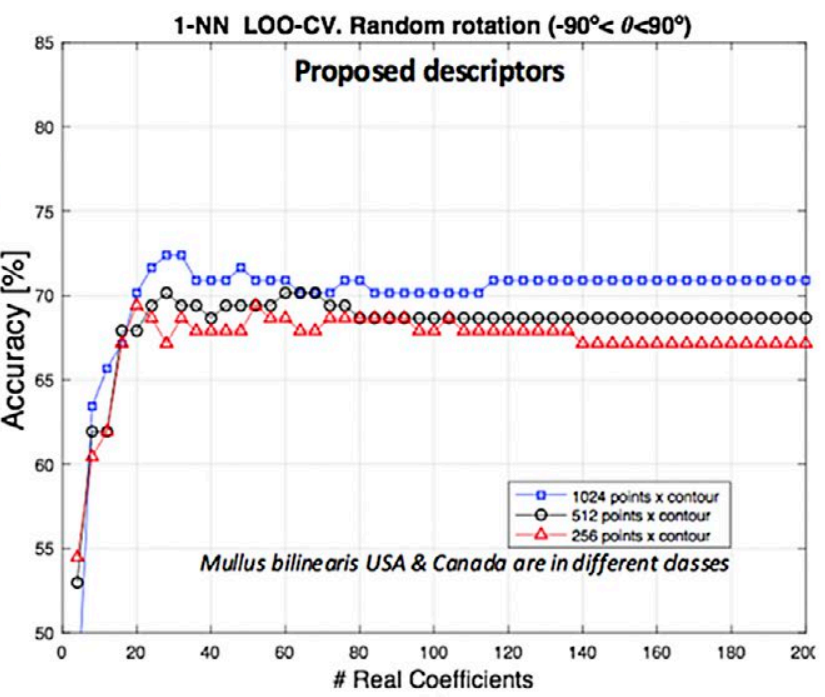

Fig. 6. $-k$-NN $(k=1)$ classification result with LOOCV for \# real coefficients employed and the number of points per contour (256, 512 and 1024). All incoming contours are randomly rotated in a range of between $-85^{\circ}$ and $+85^{\circ}$, are sampled in anti-clockwise, and have a random initial sampling point. In A, the groups of M. bilinearis collected in Canada and $M$. bilinearis collected in the USA are considered to belong to two different classes, and in B these groups are considered to belong to the same class.

A

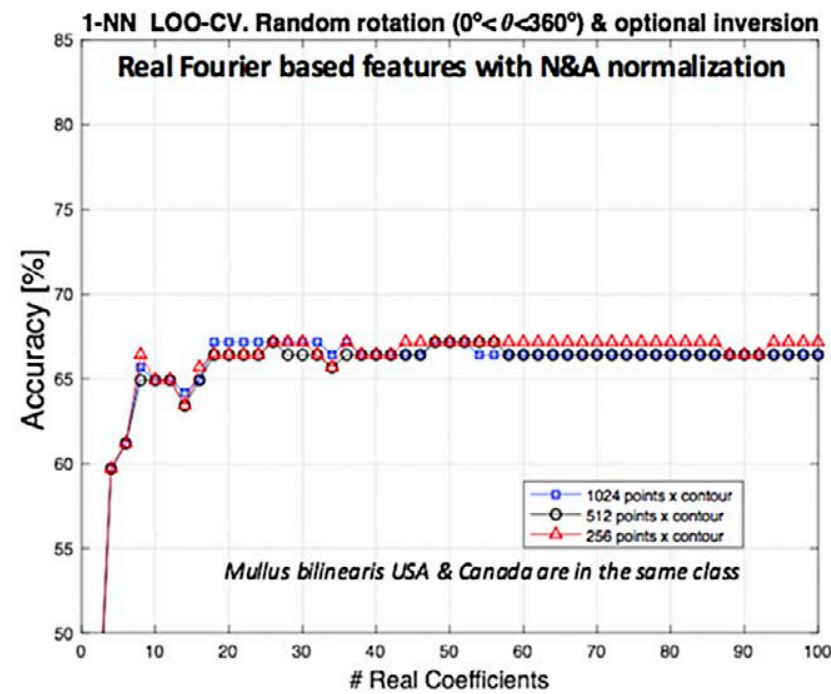

B

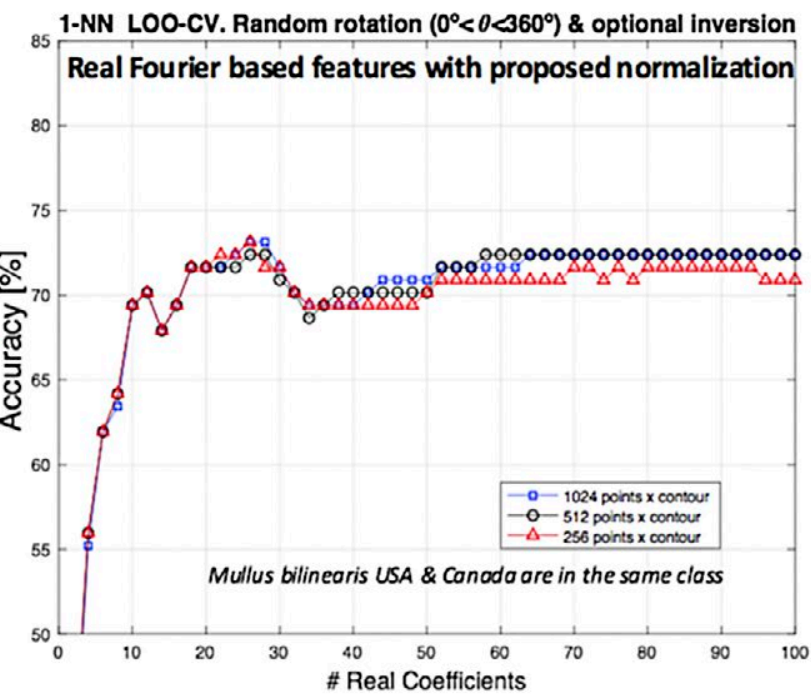

Fig. 7. $-k$-NN $(k=1)$ classification results with LOOCV for \# real coefficients employed. All incoming contours are randomly rotated $\left(0^{\circ}-360^{\circ}\right)$ and may or may not appear inverted. In A, the Nixon and Aguado normalization is employed and, in B, it is used for its own normalization.

In the most straightforward experiment completed for the second scenario, the otolith (left or right) can appear in any position and can show any face; therefore, without observing any positional normalization, the descriptors that are presented in expression (9) as well as the expressions given in Nixon and Aguado (2008, p. 307) are used. For this purpose, all the contours of the test group are parameterized in both ways, and the $1-\mathrm{NN}$ classification with the LOOCV test is carried out. The contours under the test are randomly rotated by between $0^{\circ}$ and $360^{\circ}$ and an inversion with the intention of simulating turning the otolith face is optionally applied. The accuracy regarding the number of real coefficients that are employed in the experi- ments shows that the optimum performance is observed for the range 26 to 28 real coefficients. However, the accuracy that is obtained in comparison with the first scenario has fallen considerably: from near $80 \%$ to $72.4 \%$, as shown in Figure 7.

To improve the classification results in the second scenario (avoiding the positional normalization in the query image), we propose the use of the descriptors that were developed in (8) in the following form. The contour in which the otolith appears with any normalization is sampled counter-clockwise and is parameterized according to (8), as in the first scenario. Then, from these parameters, we reconstruct the contour again, obtaining any of the forms shown in 
A

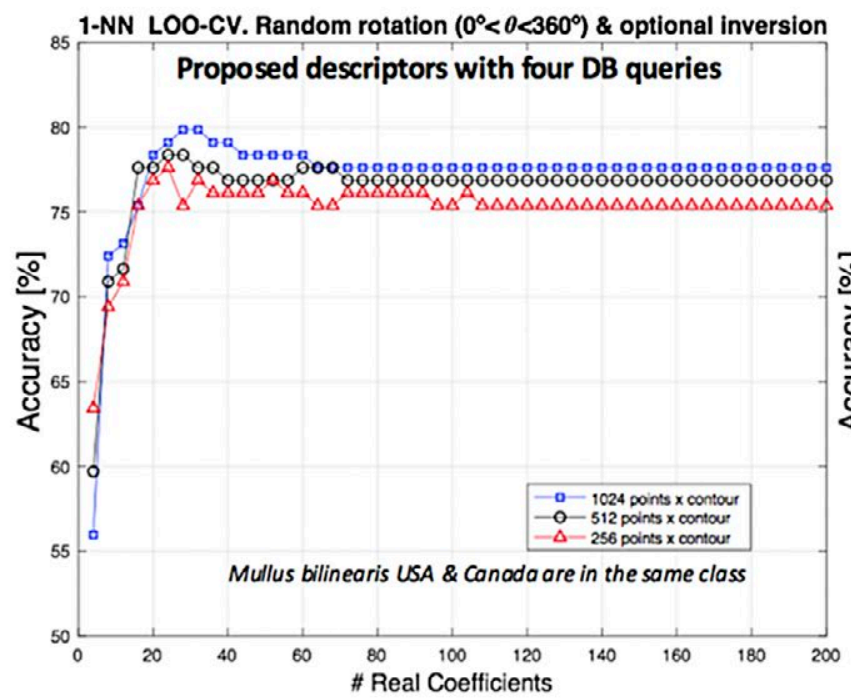

B

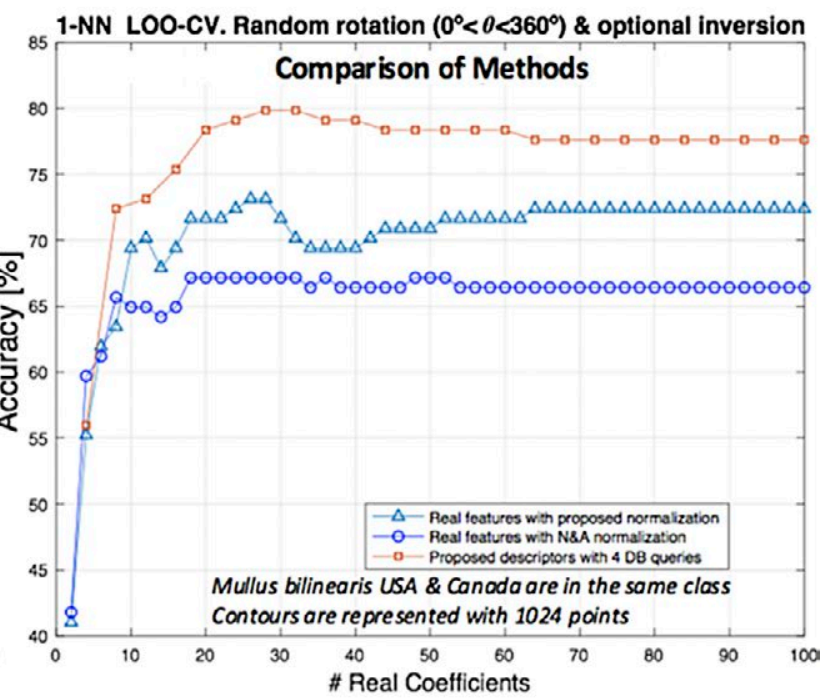

Fig. 8. - A, $k$-NN $(k=1)$ classification results with LOOCV for \# real coefficients when the second scenario is in force. The proposed parameterization applied to four related contour shapes achieves practically the same accuracy as in the first scenario. B, $k$-NN $(k=1)$ classification results with LOOCV for \# real coefficients for all full invariant methods described in the paper.

Figure 5. Thus, the contour obtained is rotated $180^{\circ}$, inverted, and inverted and rotated to obtain three other silhouettes, as shown in Figure 5. We can use a fast implementation with the ifft by using the expressions that are presented in shape symmetries and their relationship with the proposed descriptors. Those four contours are parameterized according to (8) again and are classified individually in the database, saving the four results of the classification, as well as the distance to the nearest neighbour, in such a way that the winning option is the one with the lowest distance. The option that is decided by the four generated contour shapes for a single otolith image is therefore the one that obtains the lowest distance metric.

With this procedure, the classification results are close to those obtained in the first scenario. The results can be seen in Figure 8A for the second scenario. It is interesting to note that with a similar number of coefficients applying this second strategy, we achieve the same accuracy as in the first solution. The performance of the full invariant methods that are described in the paper are plotted together in Figure 8B.

\section{DISCUSSION}

The success of automatic species recognition from the images of otoliths that are sent to AFORO requires the otolith to follow positional normalization. The determination of the contour sampling starting point depends on this. Studies that are carried out in the framework of the AFORO database show that the contour descriptors that achieve the best performances, such as those based on FT, WT, and CSS, are sensitive to the determination of that point (Marti-Puig and ReigBolano 2016). The translation and scale invariances are addressed in a non-ambiguous and straightforward way. The shape rotation with respect to the positional normalization has a more significant impact on the starting sampling point. The reason is that it allows for a certain degree of ambiguity, because it depends on the identification of the rostrum region rather than on a single point. Actually, rotational normalization depends ultimately on the criteria of an expert. Therefore, even if specialists have taken the query images, it is inevitable that slight rotational variations will appear because of the differences in criteria.

Taking advantage of the use of the well-known DFT properties that relate rotations and sampling point changes in the spatial domain with changes in DFT coefficients, and specifically in their phase, our approach outperforms other Fourier-based methods that are dependent on a strict positional protocol. The proposed parameterization directly corrects the starting point of sampling and variations of between $90^{\circ}$ and $-90^{\circ}$ with respect to the positional normalization that is required in AFORO.

To completely eliminate the positional standardization protocol (positional normalization), in the second framework we can directly employ the modules of the DFT coefficients $f_{i}$. To make them independent of the scale, Nixon and Aguado (2013) divide $f_{i}$ by $\left|f_{1}\right|$. For automatic recognition of shape contours, we achieve the best results by normalizing by $\left|f_{1}\right|+\left|f_{N-1}\right|$, as given in (9), because $\left|f_{1}\right|+\left|f_{N-1}\right|$ is a magnitude that is directly related to the length of the principal ellipse axis. However, the main contribution of this paper is that accuracy can be improved using the descriptors that are proposed in (8) by merely adding four possible variants for each contour and selecting the one that obtains the best score (the minimum Euclidean distance to the closest neighbour). From Figure 8A we observe that with only $4 \times(28-32)$ coefficients per contour (and working with 1024 points per contour) we obtain classification rates of $80 \%$. These results are for contours that can appear randomly rotated by 360 degrees and inverted. This achievement is noteworthy because they are the 
same classification rates as those obtained for manual positional normalization (Marti-Puig and Reig-Bolano 2016). It is important to note that to maintain the classification rate, we need to increase the number of points used to represent the contour. In this case, decreasing the number of points means a decrease in the classification rate (see Fig. 8A). The four related shapes include robustness to the introduction of images showing the wrong otolith face (with the SA not visible) or even the introduction of the right otolith rather than the left in the recognition system. We thus reach practically the same classification accuracy performance as the one obtained using positional normalization but, in this case the user can avoid normalization completely. Therefore, the proposed descriptors facilitate the use of AFORO and other online catalogues and could open up the range of potential users and applications, thereby eliminating irregularities and errors in the image normalization process.

\section{ACKNOWLEDGEMENTS}

This work was partially supported by the Spanish Government projects PHENOFISH with reference CTM2015-69126-2-R. The authors are very grateful to all the people who have helped in the technical development of the AFORO website, especially Emili García-Ladona, Òscar Chic, Vicenç Parisi-Baradad, Jaume Piera, Víctor M. Tuset, Josep Forest, David Otero and Roger Olivella.

\section{REFERENCES}

Agarwal M., Venkatraghavan V., Chakraborty C. et al. 2011. A mirror reflection and aspect ratio invariant approach to object recognition using Fourier descriptor. Appl. Soft Computing 11: 3910-3915. https://doi.org/10.1016/j.asoc.2011.01.020

Baldás M.I., Pérez Macri G., Volpedo A.V., et al. 1997. Morfología y morfometría de la sagitta de peces teleósteos del Atlántico Sudoccidental. I: Carangidae, Sciaenidae, Mullidae. Rev. Atlântica 19: 99-112.

Baremore I.E, Bethea D.M. 2005. A guide to otoliths from fishes of the Gulf of Mexico. NOAA Tech. Memorandum NMFS-SEFSC-599.

https://ww w.fisheries.noaa.gov/resource/document/ guide-otoliths-fishes-gulf-mexico

Bird J.L., Eppler D.T., Checkley D.M. 1986. Comparison of herring otoliths using Fourier series shape analyses. Can. J. Fish. Aquat Sci. 43: 1228-1234 https://doi.org/10.1139/f86-152

Bustos R.L., Daneri G.A., Harrington A., et al. 2012. The diet of the South American sea lion (Otaria flavescens) at Río Negro, Patagonia, Argentina, during the winter-spring period. Iheringia Sér. Zool. 102: 394-400. https://doi.org/10.1590/S0073-47212012000400005

Bustos R.L., Daneri G.A., Volpedo A.V., et al. 2014. Diet of the South American sea lion (Otaria flavescens) during the summer season at Río Negro, Patagonia, Argentina. Aquat. Biol. 20: $235-243$. https://doi.org/10.3354/ab00557

Campana S.E. 2004. Photographic atlas of fish otoliths of the Northwest Atlantic Ocean. Can. Spec. Publ. Fish. Aquat. Sci. vol 133, Canadian Sci. Publish., 284 pp. https://doi.org/10.1139/9780660191089

Capoccioni F., Costa C., Aguzzi J., et al. 2011. Ontogenetic and environmental effects on otolith shape variability in three European eel (Anguilla anguilla, L.) Mediterranean populations. J Exp. Mar. Biol. Ecol. 397: 1-7. https://doi.org/10.1016/j.jembe.2010.11.011
Cardinale M., Doering-Arjes P., Kastowsky M., et al. 2004. Effects of sex, stock, and environment on the shape of known-age Atlantic cod (Gadus morhua) otoliths. Can. J. Fish. Aquat. Sci. 61: $158-167$. https://doi.org/10.1139/f03-151

Cartes J.E., Barsanti M., Martínez-Aliaga A., et al. 2017. Recent reconstruction of deep-water macrofaunal communities recorded in Continental Margin sediments in the Balearic Basin. DeepSea Res. Part I 125: 52-64. https://doi.org/10.1016/j.dsr.2017.04.016

Casselman J.M., Collins J.J., Crossman E.J., et al. 1981. Lake whitefish (Coregonus clupeaformis) stocks of the Ontario waters of Lake Huron. Can. J. Fish. Aquat. Sci. 38: 1772-1789. https://doi.org/10.1139/f81-225

Chaine J., Duvergier J. 1931. Sur les otolithes fossiles de la Catalogne. Publ. Inst. Ciències, Institució Catalana d'Història Natural, Memòria 3: 9-38.

Cruz A., Lombarte A. 2004. Otolith size and its relationship with colour patterns and sound production. J. Fish Biol. 65: 1512-1525. https://doi.org/10.1111/j.0022-1112.2004.00558.x

Doering P., Ludwig J. 1990. Shape analysis of otoliths - a tool for indirect ageing of eel, Anguilla anguilla (L.). Int. Rev. Gesamten Hydrobiol. Hydrogr. 75: 737-743. https://doi.org/10.1002/iroh.19900750607

Fitch J.E., Brownell R.L. 1968. Fish otoliths in cetacean stomachs and their importance in interpreting feeding habits. J. Fish. Res. Board Can. 25: 2561-2574. https://doi.org/10.1139/f68-227

Furlani D., Gales R., Pemberton D. 2007. Otoliths of common Australian temperate fish: a photographic guide, CSIRO Publishing, Collingwood, 208 pp. https://doi.org/10.1071/9780643098459

Gaemers P.A.M. 1984. Taxonomic position of Cichlidae (Pisces, Perciformes) as demonstrated by the morphology of their otoliths. Neth. J. Zool. 34: 566-595. https://doi.org/10.1163/002829684X00290

Hecht T., Appelbaum S. 1982. Morphology and taxonomic significance of the otoliths of some bathypelagic Anguilloidei and Saccopharyngoidei from the Sargasso Sea. Helgol. Meeresunters 35: 301-308. https://doi.org/10.1007/BF02006138

Koken E. 1884. Ueber Fisch-Otolithen, insbesondere über diejenigen der norddeutschen Oligocän-Ablagerungen. Z. Dtsch. Geol. Ges. Band 36: 500-565.

Kuhl F.P., Giardina C.R. 1982. Elliptic Fourier features of a closed contour. Comp. Graph. Image Proc. 18: 236-258. https://doi.org/10.1016/0146-664X(82)90034-X

Lin C.-H., Chang C.-W. 2012. Otolith atlas of Taiwan fishes. National Museum of Marine Biology and Aquarium, Pingtung.

Lombarte A., Cruz A. 2007. Otolith size trends in marine fish communities from different depth strata. J. Fish Biol. 71: 53-76. https://doi.org/10.1111/j.1095-8649.2007.01465.x

Lombarte A., Fortuño J.M. 1992. Differences in morphological features of the saculus of the inner ear of two hakes (Merluccius capensis and $M$. paradoxus, Gadiformes) inhabits from different depth of sea. J. Morphol. 214: 97-107. https://doi.org/10.1002/jmor.1052140107

Lombarte A., Chic Ò., Parisi-Baradad V., et al. 2006. A web-based environment from shape analysis of fish otoliths. The AFORO database. Sci. Mar. 70: 147-152. https://doi.org/10.3989/scimar.2006.70n1147

Marti-Puig P., Reig-Bolano R. 2016. A rotation-invariant feature space according to environmental applications needs in a data mining system using fish otoliths. Al Commun. 29: 687-699. https://doi.org/10.3233/AIC-160715

Marti-Puig P., Danés J., Manjabacas A., et al. 2015. New parameterization method for 3D otolith surface images. Mar. Freshw. Res. 67: 1059-1071 https://doi.org/10.1071/MF15069

Messieh S., McDougall C., Claytor R. 1989. Separation of Atlantic herring (Clupea harengus) stocks in the Southern Gulf of St. Lawrence using digitised otolith morphometrics and discrimination function analysis. Can. Tech. Rep. Fish. Aquat. Sci. 1647: $1-22$

Monteiro L., Di Beneditto A.P.M., Guilhermo L.H., et al. 2005. Allometric changes and shape differentiation of sagitta otoliths in sciaenid fishes. Fish. Res. 74: 288-299. https://doi.org/10.1016/j.fishres.2005.03.002

Neves V.C., Bried J., Gonzalez-Solis J., et al. 2012. Feeding ecol- 
ogy and movements of the Barolo shearwater Puffinus baroli baroli in the Azores, NE Atlantic. Mar. Ecol. Prog. Ser. 452: 269-285.

https://doi.org/10.3354/meps09670

Nixon M.S., Aguado A. 2008. Feature Extraction and Image Processing for Computer Vision, Academic Press, Orlando.

Nolf D. 1985. Otolithi piscium. In: Schultze H.P. (eds), Handbook of Paleoichthyology, vol. 10, pp. 1-145. Gustav Fischer Verlag, Stuttgart.

Otalora-Ardila A., Herrera L.G., Flores-Martinez J.J., et al. 2014. Marine and terrestrial food sources in the diet of the fish-eating myotis (Myotis vivesi). J. Mammalogy 94: 1102-1110. https://doi.org/10.1644/12-MAMM-A-281.1

Parisi-Baradad V., Lombarte A., García-Ladona E., et al. 2005. Otolith shape contour analysis using affine transformation invariant wavelet transforms and curvature scale space representation. Mar. Freshw. Res. 56: 795-804 https://doi.org/10.1071/MF04162

Parisi-Baradad V., Manjabacas A., Lombarte A., et al. 2010. Automatic taxon identification of teleost fishes in an otolith online database. Fish. Res. 105: 13-20. https://doi.org/10.1016/j.fishres.2010.02.005

Piera J., Parisi-Baradad V., García-Ladona E., et al. 2005. Otolith shape feature extraction oriented to automatic classification with open distributed data. Mar. Freshw. Res. 56: 805-814. https://doi.org/10.1071/MF04163

Pierce G.J., Boyle P.R., Diack J.S.W. 1991. Identification of fish otolith and bones in faces and digestive tracts of seals. J. Zool. London 224: 320-328. https://doi.org/10.1111/j.1469-7998.1991.tb04810.x

Proakis J.G., Manolakis D.G. 1996. Digital Signal Processing. Principles, Algorithms and Applications, Prentice-Hall, New Jersey.

Ramcharitar J., Gannon D.P., Popper A.N. 2006. Bioacoustics of the family Sciaenidae (croakers and drumfishes). Trans. Am. Fish. Soc. 135: 1409-1431. https://doi.org/10.1577/T05-207.1

Reig-Bolaño R., Marti-Puig P., Lombarte A., et al. 2010. A new otolith image contour descriptor based on partial reflection. Environ. Biol. Fish. 89: 579-590. https://doi.org/10.1007/s10641-010-9700-3

Rodney H. 2009. The archaeology of the Port Hedland coastal plain and implications for understanding the prehistory of shell mounds and middens in northwestern Australia. Archaeol. Oceania 44: 81-98.

https://doi.org/10.1002/j.1834-4453.2009.tb00070.x
Sadighzadeh Z., Tuset V.M., Dadpour M.R., et al. 2012. Otolith Atlas from the Persian Gulf and the Oman Sea Fishes. Lambert Academic Publications, Saarbrucke, 55 pp.

Sadighzadeh Z., Otero-Ferrer J.L., Lombarte A., et al. 2014. An approach to unraveling the coexistence of snappers (Lutjanidae) using otolith morphology. Sci. Mar. 78: 353-362 https://doi.org/10.3989/scimar.03982.16C

Schmidt W. 1969. The otoliths as a means for differentiation between species of fish of very similar appearance. In: Proceedings-Symposium of Oceanography of Fisheries Research in Tropical Atlantic, (1966 Abidjan, Ivory Coast), pp. 393-396. UNESCO, FAO, OAU.

Smale M.J., Watson G., Hecht T. 1995. Otolith atlas of southern African marine fishes. Ichthyol. Monogr. Ser. n. 1, J.L.B. Smith Inst. Ichthyol., Grahamstown, South Africa, 418 pp. https://doi.org/10.5962/bhl.title.141860

Tuset V.M., Rosin P.L., Lombarte A. 2006. Sagittae otolith shape used in the identification of fishes of the genus Serranus. Fish. Res. 81: 316-325. https://doi.org/10.1016/j.fishres.2006.06.020

Tuset V.M., Lombarte A., Assis C.A. 2008. Otolith atlas for the western Mediterranean, north and central eastern Atlantic. Sci. Mar. 72 (Suppl. 1): 1-198 https://doi.org/10.3989/scimar.2008.72s17

Tuset V.M., Azzurro E., Lombarte A. 2013. Identification of Lessepsian fish species using the sagittae otolith. Sci. Mar. 76: 289-299. https://doi.org/10.3989/scimar.03420.18E

Tuset V.M., Farré M., Otero-Ferrer J.L., et al. 2016. Testing otolith morphology for measuring marine fish biodiversity. Mar. Freshw. Res. 67: 1037-1048. https://doi.org/10.1071/MF15052

Veiga P., Xavier J.C., Assis C.A., et al. 2011. Diet of the blue marlin, Makaira nigricans, off the south coast of Portugal. Mar. Biol. Res. 7: 820-825 https://doi.org/10.1080/17451000.2011.578648

Volpedo A.V., Echeverría D.D. 2000. Catálogo y claves de otolitos para la identificación de peces del Mar Argentino 1. Peces de Importáncia Económica. Dunken, Buenos Aires.

Zhang D., Lu G. 2001. A comparison of shape retrieval using Fourier descriptors and short-time Fourier descriptors. In: Shum H.Y., Liao M., Chang S.F. (eds), Advances in Multimedia Information Processing. PCM Lecture Notes in Computer Science, vol 2195. pp. 855-860. Springer, Berlin, Heidelberg. https://doi.org/10.1007/3-540-45453-5_111 